\title{
The music of the nanospheres
}

\author{
Jeremy J. Ramsden
}

Cranfield University, Bedfordshire, $U K$

The generally promulgated vision of nanotechnology in the future is all-encompassing. Both its proponents and opponents are united in declaring that significant developments will take place. Assessing what has already been done, one can assert the following: nanodevices are ubiquitous in electronic equipment, especially microprocessor circuits and peripheral equipment, such as random access (RAM) and read only memory (ROM) chips, and other data storage media and their associated writers and readers. That alone is enough to make nanotechnology revolutionary - but only indirectly. Elsewhere, nanomaterials, presently dominated by nanoparticles incorporated into nanocomposites, are already used in a wide range of products, which are either superior to previous versions for the same cost, or offer the same performance for lower cost. Since these products are typically mass consumer items with a global market, such as razor blades or soft drink canisters, their economic impact may be considerable, but they can scarcely be said to be revolutionary. We should spend more time considering those nanotechnologies still being developed, but which will more clearly offer novel possibilities, such as wearable electronics, and miniature, inexpensive and highly efficient fuel cells. The latter will certainly be a great convenience, reducing emissions from vehicles (in comparison to the internal combustion engine) and allowing laptop computers and mobile telephones to be used for days or even weeks before needing to be recharged, but again, as with electronics, the impact of the nanotechnology is indirect.

In the first part of this essay the typical assertions of the proponents will be briefly examined. In the second part, some key aspects of nanotechnology's far reaching possible consequences, which have so far either escaped or received little scrutiny, will be examined.

\section{The assertions of nanotechnology}

"Nanotechnology is being heralded as the new technological revolution...its potential is clear and fundamental...so profound that it will touch all aspects of the economy and society. Technological optimists look forward to a world transformed for the better by nanotechnology. 
For them it will cheapen the production of all goods and services, permit the development of new products and self-assembly modes of production, and allow the further miniaturization of control systems. They see these effects as an inherent part of its revolutionary characteristics. In this 'nano society', energy will be clean and abundant, the environment will have been repaired to a pristine state, and any kind of material artefact can be made for almost no cost. Space travel will be cheap and easy, disease will be a thing of the past, and we can all expect to live for a thousand years" (emphases added).

With these words begins the recently published report on nanotechnology, commissioned by the British Economic and Social Research Council (ESRC). ${ }^{1}$ Coauthored by distinguished academics, it attempts to soberly assess the current debate pro and contra nanotechnology. The contrasting view of the technological pessimists points to the dangers of nanoparticles penetrating into the human body and possibly overwhelming the body's defence mechanisms, of molecular assemblers running out of control and turning everything on the earth's surface into an amorphous mass ("grey goo"), and of the indirect effects of nanotechnology, such as ever more powerful digital information processing and storage devices, being used by whichever group of citizens happens to be in power to suppress the civil liberties of the rest, and to devise ever more sinister weapons for use by the military forces under the control of that ruling group.

Neither the extreme optimists nor the extreme pessimists are much concerned with the feasibility of these new technologies. They implicitly assume that they can and therefore will be developed, and explore the consequences given that assumption. Their recommended solution to the problem of containing the potential evils is strict government regulation and controlblithely overlooking the rather obvious point that the authorities they propose to entrust with overseeing the restriction of nanotechnology to what they see as socially beneficial causes are identical to those that are suspected of planning to use nanotechnology to deprive other citizens of their liberties. With not much more than a vague allusion to neo-Luddism at its core, the view of the technological pessimists has little to commend it. On the other hand, the writings of the technological optimists are eloquent and detailed, down to blueprints for the molecular assemblers. It is appropriate therefore to examine in comparable detail some of the claims of the optimists, as represented by Wood et al.'s distillate quoted above, and the first part of this essay is devoted to that.

\section{Nanotechnology is the new technological revolution}

This is a very reasonable claim. Some critics would say that nanotechnology is too allencompassing for it to be a meaningful concept — pointing out that in the past we had rather specific innovations such as the Bronze Revolution leading to the Bronze Age, and similarly with the Iron Revolution, the Steam Revolution and so on. Yet the most famous revolution of all, the Industrial Revolution, was equally all-encompassing, and the comparison is indeed not

\footnotetext{
${ }^{1}$ S. Wood, R. Jones and A. Geldart, The Social and Economic Challenges of Nanotechnology. Swindon: ESRC(2003).
} 
unreasonable, and lest other critics say that the early industrial revolutionaries lacked the hubris of today's nanorevolutionaries, one can riposte by saying that the great Victorian engineers undoubtedly possessed bucketfuls of hubris, and furthermore one is entitled to suppose that since then more wisdom has been accumulated and therefore the outcome of new technological trends can be better predicted.

\section{It will touch all aspects of the economy and society}

Again, this is a very reasonable claim. Since the nano-movement affects current core technologies such as information processing circuitry (whether electronic or photonic), materials, chemical reactors and medicine, it will indeed touch all, or practically all aspects of life. This claim is redundant once the revolutionary nature of nanotechnology has been conceded, for that is precisely the nature of revolutions, to effect a complete change.

\section{The world will be transformed for the better by nanotechnology}

This sentiment emerges in a very vague and unformulated way. It is not possible to deduce how this will come about, in any global, uncontentious sense, from most of the writings of the technological optimists. Undoubtedly the early Victorian engineers were strongly motivated by the desire to make man's habitat on earth not only more pleasant, but also grander and more inspiring. The technological revolutions of the nineteenth century led directly and indirectly to remarkable and unprecedented advances in knowledge; directly because the scientific equipment for such advances became realizable, and indirectly because that spirit of grandeur moved individual investigators to tackle the grandest and most profound problems of the structure and dynamics of the universe. Is there a parallel to that movement today?

A recent, widely disseminated report ${ }^{2}$ envisages that by the year 2020 orange juice will be packaged in "intelligent" cartons that will sense whether the contents are still fit for human consumption. This rather trivial example will suffice for analysis, since the report is full of similar ones, and it seems to be very representative of a certain widely-held viewpoint. ${ }^{3}$ That fact is that during the past decade or more the quality of orange juice has been declining. The bottom line is that the prepackaged carton - in which there is already a great deal of sophisticated technology - is at its very best a poor relation to juice freshly pressed from the oranges themselves. Most vegetables and fruits start losing components of high nutritional value within seconds of being picked or cut. It is not specified to what chemicals the proposed intelligent sensor will respond, but they will doubtless be only a tiny fraction of the totality of the complex and subtle mixture of molecules giving natural products their "goodness". The same effect—of

\footnotetext{
${ }^{2}$ Nanotechnology: Innovation for Tomorrow's World. Brussels: European Commission (2004); (first published as Nanotechnologie. Bonn: Innovationen für die Welt von morgen. Bundesministerium für Bildung und Forschung (2004)).

${ }^{3}$ One should perhaps be cautious and merely state that this view it is promoted by that segment of the community that writes such reports, but at any rate it has not been pointedly disavowed by the rest of the community.
} 
guaranteeing the presence of a small subset of chemicals, and the absence of harmful onescould be achieved far more reliably and economically by dispensing a tablet formulated from those chemicals, which would simply be added to water. If the nano-vision of the European Commission is limited to providing, 15 years hence, "intelligent" packaging for a beverage of dubious quality and mediocre taste, one would be fully justified, as a member of the public, in questioning the need for providing expensive research facilities to develop the necessary technology. What is needed is a fresh vision of the system of growing and distributing agricultural products. Nanotechnology, or indeed any other kind of technology, is scarcely needed for solving the problem of ensuring the reliable supply of wholesome and nutritious food. Incidentally, this example also illustrates the vital necessity of a pluridisciplinary approach, since apart from materials and devices, knowledge of economics and commerce must be brought to bear, and agronomy too - the deplorable quality of many commercially grown oranges, at least by the time they reach the market or supermarket, being another contemporary problem.

The vision of nanotechnology in future everyday life promulgated by this report ${ }^{4}$ is anything but grand and profound, and might be described as a nursery vision of utopia blended with elements from George Orwell's 1984. The citizens of the European Community deserve a better fate than that, one would hope. We shall return to this topic in the second part of this essay.

\section{The production of all goods and services will be cheapened}

Technologies in general tend to become adopted because production costs can be reduced with them. As it stands, therefore, the statement is unexceptionable. Under the mantle of extreme or strong nanotechnology, however, it is claimed that any kind of material artefact can be made for almost no cost. The enabling technology behind this development is supposed to be molecular assemblers ${ }^{5}$ - and it would be almost equally plausible (or implausible) for sophisticated self-assembly technology to be used as a universal construction procedure. ${ }^{6}$

Indirectly, if energy will not only be clean and abundant (see below), but also cheap, that in itself would powerfully drive down manufacturing costs.

\section{Energy will be clean and abundant}

Nanotechnology contributes to energy production in two main ways: sophisticated nanoparticles as components of photovoltaic (Grätzel) cells for generating electricity, or possibly hydrogen, from sunlight; and sophisticated nanocomposite materials as used in the various components of fuel cells for generating electricity directly from the oxidation of liquid fuels, or possibly hydrogen. A cycle in which sunlight is used to reduce water to hydrogen, in which form the energy would be stored until oxidized by fuel cells to generate electricity, would be very

\footnotetext{
${ }^{4}$ Ibid., pp. 28-29.

${ }^{5}$ Minute, self-replicating machines able to fabricate any artefact atom by atom.

${ }^{6}$ One should however note that whereas at least some theoretical work has been carried out on the assemblers, only the most rudimentary steps have been taken in that regard for self-assembly processes.
} 
clean - leaving aside the question of how the components for those devices would be manufactured.

Since miniature devices use less energy than large ones, global energy requirements should progressively fall as nanotechnology pervades the world.

\section{The environment will have been repaired to a pristine state}

The connexion between environmental remediation and nanotechnology is far from obvious. Top down nanofabrication is not especially environmentally friendly, although it is certainly beneficial that silicon, the currently favoured material for nanodevices, whether they work electrically, optically or machanically, happens to be one of the most abundant materials in the earth's crust.

The closest connexion seems to come through what has been called conceptual nanotechnology — viewing the world from the molecular viewpoint, which, when applied to remediation technologies such as phytoremediation (which, alone among its rivals, has the possibility to become a universal remediation technology, simply because plants are so ubiquitous on our planet) results in molecular and ultrastructural mechanistic explanations of how the process works. ${ }^{7}$ These explanations of course enormously enhance the power of the technology since the plants selected can then be properly matched to the remediation task in hand.

Once that pristine state has been attained (and, be it admitted, there is no evidence that it is even being approached at present: beyond a few successes in cleaning up rivers, environmental degradation continues to progress) it should be easier to maintain than at present: the environmental footprint of molecular manufacturing is much, much smaller than that of conventional techniques, and if waste is decomposed into its constituent atoms, all of which are then used as raw materials for manufacturing, then perfect sustainability will indeed have been achieved.

\section{Space travel will be cheap and easy}

Here, evidently, the indirect benefits of nanotechnology are alluded to: low cost hydrogen, ultrastrong, light and heat-resistant nanocomposites, nanodevice instrumentation (including optical and quantum computers) and so on.

\section{Disease will be a thing of the past}

“...and we can all expect to live for a thousand years." The tremendous progress made by medicine in recent decades in the technology of life support, repair and prostheses, surgical intervention, ways of measuring static structures and dynamical processes (especially with sophisticated tomographies), pharmaceuticals etc. owe little to nanotechnology. Indirectly, due to its enabling of ever more powerful data processing and storage devices (due to progressive

\footnotetext{
${ }^{7}$ For an up to date review, see G. Kvesitadze et al., Mechanisms of Detoxification: the Basis of Phytoremediation. Heidelberg: Springer (2005).
} 
miniaturization) nanotechnology has certainly contributed, and many more improvements are on the way, e.g. novel nanocomposites for prostheses with enhanced biocompatibility, novel nanocomposites for controlled and targeted drug delivery, genetic modification via manipulating DNA using the atomic force microscope, and, most strikingly, sophisticated nanodevices able to travel within the human body and carry out repair work.

Nevertheless, some limitations will doubtless remain. The history of medicine shows that technological improvements generally focus attention on the organ requiring treatment, and tend to diminish consideration of the body and spirit of a person as a whole - as was already lamented by pioneering physicians such as Hohenheim in the sixteenth century. ${ }^{8}$ Perhaps parallel advances in brain science - again indirectly facilitated by nanotechnology — will encourage a more complete view of a human being from the medical perspective.

\section{Summary (Part 1)}

Some of the claims made for the future impacts of nanotechnology are actually based on extrapolating current trends in the advance of all technologies, to which nanotechnology is only contributing a part. To be sure, the tremendous growth in data processing and storage capability, largely enabled by the relentless miniaturization of top down semiconductor fabrication technology, is indirectly responsible for most of the advances made nowadays, but the scale now reached by that technology just happens to have entered the realm of the nanometre, and is best described as a progression rather than a revolution. In other fields, where nanoparticles or nanostructuring are indeed being applied, the applications are as yet of minor importance: improved sun cream or ties that cannot be dirtied can hardly be said to constitute a revolution.

The really revolutionary advances such as universal molecular manufacturing, either using molecular assemblers or programmable self-assembly, have yet to be brought to fruition. Manufacturing on that basis really would constitute a revolution — one that will require, or bring in its train, the entire reorganization of society. That is the topic to which we shall now turn.

\section{What do we hope to achieve with nanotechnology?}

Ever since the dawn of humanity man has struggled to improve the efficiency of the means he has at his disposition to survive, so that by some means he may win leisure time and not be obliged to spend all his waking hours on sheer survival. That is the aim of technology. A knife can cut faster than gnawing, an axe faster than nibbling, and so on. And, when sufficient leisure is available, some of it is used to reflect on the world about us, knowledge begins to advance, which in turn can further advance labour-saving technology, and so on. ${ }^{9}$ Once this progression

\footnotetext{
${ }^{8}$ J.J. Ramsden, "Paracelsus: the measurable and the unmeasurable”. Psyche: Problems, Perspectives 4 (2004) $52-58$.

${ }^{9}$ J.J. Ramsden, The New World Order. Moscow: Progress Publishers (1991).
} 
has been nucleated, empirical examination of history shows that it is difficult to arrest; indeed it constantly accelerates, since the advance of knowledge is used to develop new technology, which further increases the efficiency of production, and provides yet more leisure time, and so on. ${ }^{10}$ The progression will presumably continue as long as the benefits of technology outweigh the disadvantages, such as pollution and environmental degradation — were that not the case, the technology would presumably be abandoned. ${ }^{11}$

If indeed self-replicating nano-assemblers can produce all our daily needs up to an arbitrarily sophisticated level from waste and sunlight, then technological progression will thereby have reached its apotheosis. Leisure will occupy all our time - presumably just some slight advances in the technology will still be required, since presumably our daily needs will evolve as a result of people thinking during their leisure hours, so a small corps will still have to work on modifiying the technology accordingly.

How will society be organized in such a situation? The first image that comes to mind is the world created by E.M. Forster in his short story The Machine Stops, ${ }^{12}$ in which humans lived in individual underground cells, essentially travelling only for the purpose of regulated reproduction, and devoting their time to thinking and listening to and delivering lectures by and to their friends.

It is a dismal and dangerous image, for in such a society evolution has come to a virtual standstill, rendering the whole system vulnerable to any external catastrophe, and even to an internal one. In Forster's story, such an internal catastrophe caused the death of nearly everyone, with just a hint of possible rebirth from a tiny group of people who had previously escaped from the underground cell mode of existence.

Such social models are not, in fact, sustainable, any more than the society created in Orwell's 1984. The nub of the difficulty lies in the phrase above, "a small corps will still have to work on [advances in the technology]." That small corps will have to retain a vigorous, creative way of thinking - and have experimental facilities appropriate to their level of theory. Were man immortal such a corps could, once formed, continue indefinitely, but since man is not, there has to be an arrangement for regenerating the corps. Sir Lawrence Bragg has estimated that the yield of physicists able to carry out independent research is one per annum per four million people. This is for a country (Britain) with a sophisticated educational system. If that 'small corps' were constituted from just 60 people, there would have to be one or two new recruitments every year, and each new recruit would have been the product of four million boys and girls at school and undergoing higher education, to sustain which a far larger corps of teachers and professors would be required, many of whom would themselves have been the product of a similar process of distillation and concentration.

\footnotetext{
${ }^{10}$ Note that this mechanism provides no clue to the collapse of technologically advanced societies, such as the Roman empire.

${ }^{11}$ The pollution may however occur in a place spatially distinct from that of the beneficial application of the technology. A conscious decision to abandon technology because of deleterious effects, as in as in Samuel Butler's Erewhon, requires a more politically cohesive world than we have at present.

${ }^{12}$ London: Sidgwick \& Jackson (1947).
} 
There is no need to argue from works of fiction to demonstrate the validity of these points. The Soviet Union, the model for 1984, found itself in precisely such a situation. For the purposes of national defence it was obliged to create a corps of mostly physicists, engineers and mathematicians who worked on projects such as the atomic and hydrogen bombs, and the government was obliged to ensure that that this corps retained full intellectual freedom, without which their creativity and hence power to produce workable solutions to the problems before them would have withered away. This very necessary freedom of course frequently discomfited the ruling elite; and in order to ensure a healthy sustainability of that corps, a highly effective educational system had also to be built up and sustained.

The conclusion we can draw is that any technological system powerful enough to essentially enslave humanity requires, for its sustainment, vigorous independent scientific thinking, and since enslavement would destroy the creativity of those scientists, the seeds of freedom will forever be built into the system. It is in this light that we should perceive the potential of nanotechnology to dominate and enslave.

Having thus dismissed the Orwellian vision of the future, we have to ask what alternative presents itself. It is to that question that we now turn.

\section{What could a nanotechnology society look like?}

The general impact of any powerful new technology is to increase the amount of leisure time available to mankind. The notion that humanity's lot is mainly hard work, extracting a meagre living from an unsympathetic environment, is well captured by the divine command following man's expulsion from the Garden of Eden, "In the sweat of thy face shalt thou eat bread, ...". 13 That state indeed seems to characterize the dawn of civilization. But man had eaten the fruit of the tree of knowledge, and Buckle has eloquently argued that the entire advance of civilization has been the result of the growth in our knowledge about the universe and, concomitantly, about ourselves $;{ }^{14}$ whereas our moral perceptions have remained essentially static for thousands of years. As outlined above, a fraction of each hard-won increase in leisure time is devoted to advancing knowledge, part of which is turned into new technology, which generates more leisure time, and so on.

The most prominent examples of the results of the technologies of antiquity known to us are the massive contructions that remain standing to this day in Egypt, Mesopotamia and elsewhere. They well exemplify the tradition of engineering technologies continued by the Romans, in which nature was reshaped block by block, each placed with unwavering intent to create artificial mountains and rivers - the pyramids and aqueducts. The disparity between the impressive engineering achievements of the Romans and the meagre core of what we would call fundamental physics, chemistry and biology is too well known to require further comment here; what we think of as fundamental advances apparently required the invention of the modern

\footnotetext{
${ }^{13}$ Genesis 3, 19.

${ }^{14}$ The History of Civilization in England. London: Longmans, Green \& Co. (1869). 
scientific method, which took place in the new European universities founded from the eleventh century onwards. ${ }^{15}$ The rest is well known; in particular, although the fundamental knowledge base became vastly more sophisticated, technology was still based on control and mastery over nature, which, following the invention of steel and the steam engine seemingly knew no bounds. Our currently most advanced technology, that of information processing, is still based on that principle: by means of immutable lines of code, we instruct the computer to do exactly what we want, neither more nor less, and that code is implemented on equally immutable arrays of circuit elements on silicon chips. Exactly the same trend is observable in those technologies that interface more closely with nature. Thus was the meandering Rhine straightened and canalized, the wilderness of the primaeval forest turned into crop monoculture, and the seeming chaos of DNA ordered by genetic engineering.

We seem now to be reaching the limits of what can be achieved in that direction. Particularly in processor circuit design and programming, chips are becoming too complex to be able to continue to maintain absolute control over information flows within them. Regarding agriculture and large scale engineering works, there is perhaps still the feeling that errors and deficiencies can be overcome by yet more control, but here there are also limitations - of physical (Euclidean) space. Interestingly enough, nanotechnology is widely considered to have been launched, in spirit if not in name, by a lecture entitled "There's plenty of room at the bottom" given by R.P. Feynman in 1959, as if already then there was a feeling that humanity was running out of space. What better solution to the problems of an overcrowded world than to relegate manufacturing to the invisible, submicrometre realm, creating an army of miniature mechanical Morlocks to carry out humanity's behest?

Nanotechnology is predicted by both its promoters and detractors to be a "unique and overwhelmingly powerful force that will affect all aspects of social life". ${ }^{16}$ The neutral view merely sees nanotechnology as continuing existing technological trends. Curiously, the promoters are remarkably unimaginative in their vision of the nanotechnology age. We are promised better (quieter and more comfortable) cars and aeroplanes, and cravats and windows that do not need washing. The more ambitious promoters enthuse over "smart" clothes that autonomously respond to changes in fashion, without considering that the vastly increased amount of leisure time available to most people should also increase the amount of time that they can spend in thinking, and hence perhaps becoming more rationally dismissive of fashion. They worry, in a scenario of universal plenty, about the necessity for companies to make profits, without considering whether the joint stock company will continue to be the most appropriate and advantageous way of organizing commerce. They view nanotechnology as offering new capabilities for military forces to develop 'uninhibited combat systems to enhance national security', without considering whether 'national security' will still have any meaning in an

\footnotetext{
${ }^{15}$ Jean Buridan at the Sorbonne in Paris, who was active in the fourteenth century, may be considered as a key figure in this development.

${ }^{16}$ ESRC report, ${ }^{1}$ p. 42.
} 
individualized, globalized world. In other words, the vision constructed by the promoters is one of dismal banality, based on an extremely unadventurous extrapolation of present trends, ignoring the limitations in those trends that have become rather obvious to many observers. It is a vision in which $99 \%$ or more of the potential of nanotechnology is thrown away.

It has already been pointed out that nanotechnology represents the convergence of physics, chemistry, biology and engineering. This convergence goes well beyond the purely technical aspects of nanotechnology. The notion of 'technological convergence' has previously been advocated as the basis of policy (of technologically advanced countries vis-à-vis less advanced ones). Since countries sharing common technologies become interdependent, the best way of ensuring peaceful coexistence is to share one's technology. ${ }^{17} \mathrm{China}$ and India are wholeheartedly embracing nanotechnology. In such a world, the possible need for 'uninhibited combat systems' should scarcely be a priority.

The joint stock, limited liability company was particularly well adapted to the technology of the Industrial Revolution, requiring as it did vast concentrations of capital and introducing as it did the potential for vast catastrophes. Nevertheless, it can hardly be supposed that it represents the ultimate development in commercial organization, and the energies of those who fret over whether companies can still make profits in the world of nano-assemblers could more fruitfully turn their attention to devising alternative legal frameworks for commercial activity, or to the question of whether such activity is needed at all, if every individual can make all that he or she requires from a private, solar-powered assembler.

The revolution in communications, epitomized by the internet as the apotheosis of a trend that began with the humble electric telegraph, has been the primary mover in reorganizing society in a way that is more globalized but more individualized at the same time. Is this a paradox? In its early days globalization was seen as a commercial development antithetical to the interests of the private citizen, putting him at the mercy of vast, anonymous (in the sense that the identities of their directors might not be known) international limited liability corporations. With turnovers exceeding the gross national products of many countries, they are seen by some as transcending the legal frameworks of those countries (and their "democratically elected" governments), and hence able to do whatever they wanted - it being tacitly assumed that their priority was profits rather than works beneficial to mankind. ${ }^{18}$ This viewpoint, however, naïvely neglects the reality that only such giant corporations are able to afford the giant capital investments in semiconductor processing plant needed to enable the mass production of affordable microprocessor chips. Those advocating the dismantling of giant global corporations must also, then, advocate a return to the general level of technology of two hundred years ago.

Ever since the Industrial Revolution, there have been strong advocates of doing just that. The concentration of capital-intensive technology of the early industrial age inevitably implied the

\footnotetext{
${ }^{17}$ Cf. E. Ostrum et al., The Drama of the Commons. Washington D.C.: National Academy Press.

${ }^{18}$ A not wholly unjustifiable viewpoint: as A. Weir has pointed out, "beneficial undertakings had been proved profitable; [later] it was assumed that a business, as long as it is profitable, does not require to be proved beneficial." The Historical Basis of Modern Europe. London: Swan, Sonnenschein, Lowrey (1886).
} 
construction of factories, which were seen by many as 'dark, satanic mills' ${ }^{19}$ Perhaps the most eloquent opponent of the new technological era - synonymous with the Industrial Revolutionwas John Ruskin. He argued powerfully in favour of hand-made production, an argument that later led to the Arts and Crafts movement. Undoubtedly, that movement resulted in designs of great power, beauty and practical functionality. ${ }^{20}$ Although the movement certainly enhanced and beautified our environment, it could not solve the problem of doing so on a mass scale. Moreover, although the quality of simple articles for daily household use might be higher when made individually by hand than en masse by machine, the same could not be said for a microprocessor chip. There were, moreover, even in Ruskin's day proponents of simplified production, who rejected decoration and embellishment, for reasons of rationality, not profit. ${ }^{21}$

In the time of Madách and Ruskin, the most perceptible forms of technology were the gigantic new constructions of iron and steel — great bridges, ships and the all-pervasive railways. Their dimensions and masses were many orders of magnitude greater than those of a human being. Accidents occurred. For perhaps the first time in human history, awesome mechanisms could take life away in the midst of civilian society. By the time the motor car had become established, i.e. in the 1920s, in the USA alone some 6000 lives were being lost annually through motoring accidents. Respect for human life had indeed been lost through technology, fully vindicating Ruskin's view. But by that time technology had worked itself into society; it was part of, indeed it was the system, and could not be exorcized. Not that there was any strong wish to do so. Max Frisch has wittily pointed out that technology is the knack of so arranging the world that we do not experience it. Whether through air-conditioners, or urban underground railways, this is apparently what most people want.

If the technology of the industrial revolution focused on the ultralarge, the nanotechnology revolution will focus on the technology of the ultrasmall. In that regard it makes a decisive break with the past. That microprocessors are still produced in giant, capital intensive plants (top down nanotechnology) is of diminishing relevance: the clearly stated goal of the technology is small-scale manufacture, either using molecular assemblers (miniature fabrication machines) or self-assembly. Although large numbers of items will require large scale parallel production, there is no particular requirement for that production to be localized in one place, provided that all assemblers receive the same set of instructions. Facilitated information transfer (communication) is not only enabled by nanotechnology, it is also required by it. The ideal of the technology is localized production at the point of use. It thus, for the first time in human history, offers an advanced realization of the ideal of E.F. Schumacher. ${ }^{22}$ The 'uniqueness' of nanotechnology

\footnotetext{
${ }^{19}$ From William Blake, The New Jerusalem.

${ }^{20}$ An excellent example is the house at 48 Storey's Way, Cambridge, built by Mackay Hugh Baillie Scott for Herbert Ainslie Roberts, then Secretary to the Cambridge University Appointments Board.

${ }^{21}$ As in the coolly rational world of Imre Madách's phalanstery (Scene 12 of the Tragedy of Man), in which the scientist asks, 'Tastes water fresher from a painted cup/Is rest more easy in a painted chair?/Now all is fashioned by machinery/In forms of service and simplicity.' (from G.W.H. Horne's translation). Madách also forsaw the inevitable dehumanizing aspects of such a world.
}

${ }^{22}$ Small is Beautiful. London: Blond \& Briggs (1973). 
principally comes about through its smallness in that sense. By enabling personalized manufacture, it rehumanizes technology. Nanofactured articles need no longer be of the same stamp, as epitomized by Henry Ford's decision to offer only black 'Model T' automobiles, but can be individualized at whim. This is an especially attractive prospect in medicine: nanosensors will establish a person's gene and expressed protein repertoires, and nanoreactors will synthesize the appropriate drugs in case of sickness. At a stroke, this mode of manufacturing will solve a host of other problems: desktop nanofacture using as raw material supplies from desktop garbage annihilators will largely eliminate the need for the vast transport industry, which imposes such a terrible burden on the environment.

\section{Do we want to strive for nanosociety?}

Many of the claims made for the likely impacts of nanotechnology on society seem to be not only extravagant but also wildly improbable; and above all they are not even desired by most people. The most pressing problem with which humanity is presently faced is not how to avoid cleaning windows, but how to preserve our environment in a form that can sustain human life. If $99 \%$ of the ton-miles currently transported hither and thither could be eliminated, as well as most primary extraction and garbage disposal, that problem will have been largely solved. That will be a very significant contribution of nanofacture - although we are still very far from achieving the goal of mass desktop production. Health is for many a proccupation, but the major health problems of today are probably those caused by over-sedentary lifestyles (immobility in front of a screen, or behind a steering wheel), and it might be simpler to change those lifestyles than endow ourselves with swarms of nanobots to effect repairs to our bodies. Technology frustration is another significant problem, due to decreasing human control over software of ever increasing complexity. Here, the time is more than ripe for the introduction of open-ended, selfevolving software that would deliberately sacrifice human control to achieving more powerful algorithms - for which self-assembly (of instructions) will be as powerful a concept as it will be for nanofacture. Perhaps one need not be unduly concerned about the way society will reorganize itself in response to these technological developments, for it has always shown itself to have sufficient capacity to appropriately self-evolve. 